\title{
Very Late Stent Thrombosis in a Patient Presenting with Acute Carbon Monoxide Poisoning
}

\author{
Selçuk Öztürk', Selim Ayhan², Ibrahim Dönmez², Fatma Erdem², Alim Erdem² \\ 'Department of Cardiology, Ankara Research and Training Hospital, Ankara, Turkey \\ 2Department of Cardiology, Abant Izzet Baysal University Izzet Baysal Research and Training Hospital, Bolu, Turkey
}

\begin{abstract}
Introduction: Carbon monoxide (CO), which is commonly referred to as the silent killer, can cause deleterious and unwanted cardiac effects. Some of these are arrhythmias, acute myocardial infarction (AMI), cardiogenic shock, heart failure, and pulmonary edema.

Case Report: A 50-year-old man, complaining of dyspnea and chest pain, presented to the emergency room approximately half an hour after exposure to fire smoke. He had a history of anterior myocardial infarction 3 years previously and had been treated with a tacrolimus-eluting stent at that time. On admission, electrocardiography showed ST segment elevation in the leads D1, $\mathrm{aVL}$, and $\mathrm{V} 1-3$, and ST segment depression in the reciprocal leads. The patient was transferred to the cardiac catheterization laboratory, and coronary angiography revealed stent thrombosis in the proximal part of the left anterior descending artery, causing 100\% occlusion. The patient underwent successful balloon angioplasty and stenting. For the treatment of acute CO poisoning, he was administered oxygen. The patient's condition continued to be stable, and he was discharged from the coronary intensive care unit.
\end{abstract}

Conclusion: Patients who have undergone coronary stenting, particularly those in whom drug-eluting stents have been implanted, should be carefully investigated for AMI, stent thrombosis, or any other cardiac complications in the emergency room after CO poisoning.

Keywords: Carbon monoxide poisoning, anterior wall myocardial infarction, drug-eluting stent

Received: 12.01.2016 Accepted: 07.09.2016 Available Online Date: 03.11.2016

\section{Introduction}

Carbon monoxide (CO) is known to be an inodorous, colorless, and non-irritating gas. It is commonly known as the silent killer. The toxicity of CO has been known for years, and it is one of the main causes of unintentional poisoning deaths in European countries. The main pathophysiological mechanism is dependent on the capability of CO to bind to hemoglobin with a high affinity, which displaces oxygen and forms carboxyhemoglobin ( $\mathrm{COHb})$, in which oxygen cannot be delivered to the cells. The brain and the heart, which are more prone to injury, need more oxygen than the other organs; therefore, neurological and cardiovascular manifestations are the most common results of acute $\mathrm{CO}$ poisoning. The cardiac effects of CO poisoning include angina, arrhythmia, cardiomyopathy, cardiogenic shock, and even sudden death (1). Acute myocardial infarction (AMI) secondary to $\mathrm{CO}$ poisoning is frequently reported in the literature; however, there are no published data of very late thrombosis of tacrolimus drug-eluting stents with acute CO poisoning $(2,3)$. Here we describe a case of very late stent thrombosis in a patient with CO poisoning.

\section{Case Report}

A 50-year-old man presented to the emergency room approximately half an hour after exposure to fire smoke. On admission, he complained of dyspnea and retrosternal chest pain. Physical examination revealed a heart rate of 90 beats/min, blood pressure of 132/89 $\mathrm{mmHg}$, bilateral rales (crackles) in the lower lung zones, and S1 and S2 with a regular rhythm and without murmurs, S3, or S4. His arterial blood gas analysis results were consistent with metabolic acidosis. Electrocardiography (ECG) showed ST segment elevation in leads D1, aVL, and V1-3 and ST segment depression in the reciprocal leads (Figure 1). Initial labora- 

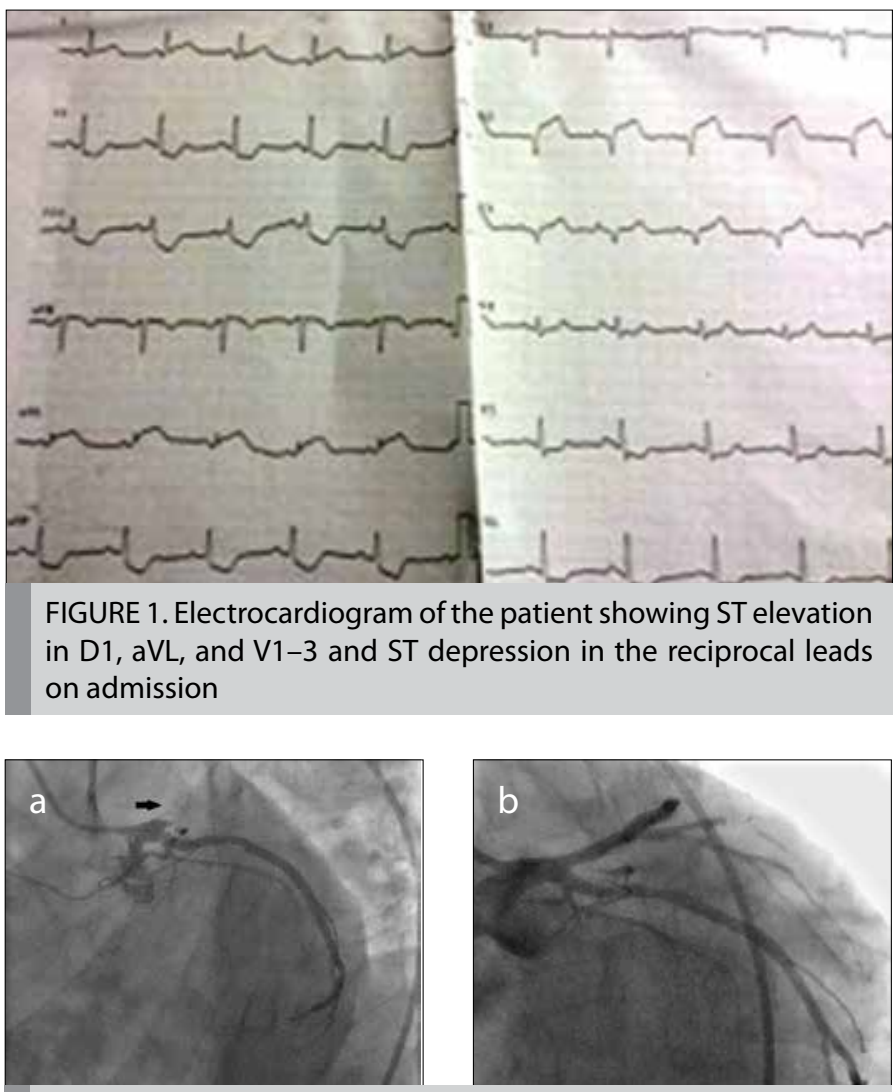

FIGURE 2.a, b. (a) Left coronary angiography demonstrating total occlusion of the proximal part of the left anterior descending artery, with stent thrombosis (black arrow). (b) Left coronary angiography after intervention demonstrating restored thrombolysis in myocardial infarction-3 flow after angioplasty with stenting

tory analyses revealed the following: troponin I level $0.122 \mathrm{ng} / \mathrm{mL}$ (normal range: 0-0.06 ng/mL) and creatine kinase-MB level $63.3 \mathrm{U} / \mathrm{L}$ (normal range: $0-24 \mathrm{U} / \mathrm{L}$ ). The $\mathrm{COHb}$ level was $20.7 \%$. The remaining blood counts and biochemistry results were within normal ranges. It was learned from his history that the patient had presented with an anterior AMI 3 years previously and had undergone successful percutaneous intervention with a single tacrolimus-eluting stent $(3 \times 19 \mathrm{~mm})$ in the proximal part of the left anterior descending artery (LAD), which was found to be an optimal stenting implantation from the hospital records. At that time, he had been discharged from the hospital with dual-antiplatelet therapy consisting of oral administration of clopidogrel $75 \mathrm{mg}$ and acetylsalicylic acid 100 mg, but clopidogrel had been stopped 1 year later. In addition, he had been prescribed atorvastatin, metoprolol, and ramipril. Three months after stenting, he presented to the hospital with chest pain and had been hospitalized with the diagnosis of unstable angina pectoris. Angiography revealed non-critical lesions and no stent re-stenosis at that time. He had been followed up as stable at the cardiology polyclinic since then. The patient received acetylsalicylic acid $300 \mathrm{mg}$ and $600 \mathrm{mg}$ clopidogrel orally and $5000 \mathrm{U}$ unfractionated heparin intravenously in the emergency room. For the treatment of acute $\mathrm{CO}$ poisoning, he was administered oxygen with a $\mathrm{FiO} 2$ of $100 \%$ via a non-rebreather mask. The patient was transferred to the cardiac catheterization laboratory, where coronary angiogra- phy revealed stent thrombosis in the proximal LAD, causing 100\% occlusion (Figure 2a). He underwent successful balloon angioplasty $(3 \times 20 \mathrm{~mm})$ and stenting with a zotarolimus-eluting stent $(3 \times 30$ $\mathrm{mm}$ ) (Figure 2b). He was then transferred to the coronary intensive care unit, and medical treatment was continued, including aspirin, clopidogrel, atorvastatin, metoprolol, ramipril, and oxygen therapy via a non-rebreather mask. After stenting, ECG showed resolution of the ST segment elevation and revealed that the patient was symptom-free. The echocardiogram demonstrated septal and anterior wall hypokinesia of the left ventricle, with an ejection fraction of $45 \%$. Follow-up laboratory tests also revealed a peak in the cardiac enzymes (troponin I>25 ng/mL; creatine kinase-MB: $135.4 \mathrm{U} / \mathrm{L}$ ). The patient's condition continued as asymptomatic and hemodynamically stable, and he was discharged after 4 days. Written informed consent was obtained from the patient.

\section{Discussion}

To the best of our knowledge, there are no published data regarding very late thrombosis of a tacrolimus drug-eluting stent in the setting of acute $\mathrm{CO}$ poisoning. It is known that $\mathrm{CO}$ can cause neurological and cardiovascular complications. Numerous harmful cardiac effects of $\mathrm{CO}$ poisoning have been published in the literature, including angina, myocardial injury, arrhythmia, cardiomyopathy, cardiogenic shock, and even sudden death (1), but there is not much evidence about very late stent thrombosis.

Different mechanisms have been demonstrated concerning CO causing myocardial ischemia. CO attaches to hemoglobin with great affinity. This causes $\mathrm{COHb}$ formation and impairments in the oxygen transport system, which lead to tissue hypoxia $(1,4)$. Furthermore, $\mathrm{CO}$ also binds to the proteins myoglobin and cytochrome-c oxidase, which are found in the cardiac and skeletal muscles. This situation interrupts muscle oxygen transport and causes consequent hypoxia (3). If $\mathrm{CO}$ binds to cytochrome-c oxidase, it results in contractile dysfunction of the myocardial cells $(5,6)$.

Hypoxic injury, neurological damage, and possible death can occur after inhaling even relatively small amounts of $\mathrm{CO}$, particularly in patients with high cardiovascular risk. Toxicity also increases, depending on the previous history of cerebral or cardiovascular diseases and of conditions that lead to high metabolic rates (7). Our case had a history of stent implantation due to AMI 3 years ago and of a reduced ejection fraction.

CO has prothrombotic potential and may trigger thrombus formation in the arterial and venous systems. CO binds to fibrinogenbound heme and this situation affects the coagulation cascade. Secondly, an increased aggregation of platelets and polycythemia after CO poisoning can cause thrombus formation. The increase in viscosity, polycythemia, and thrombogenicity can be the cause of myocardial injury, even in the presence of normal coronary arteries $(8,9)$. In our case, we cannot suggest that the formation of stent thrombosis is due to $\mathrm{CO}$ poisoning, but we can speculate that the combination of these events may be related. Dileo et al. reported a 50-year-old patient presenting with ST segment elevated AMI and late stent thrombosis (sirolimus drug-eluting stent) in the setting of $\mathrm{CO}$ poisoning. They treated the patient successfully with balloon angioplasty (2). In another case report, Hsu et al. described a patient 
presenting to their clinic with AMI secondary to $\mathrm{CO}$ poisoning. The patient did not have coronary artery disease previously, and they treated the patient successfully with balloon angioplasty (3).

\section{Conclusion}

CO poisoning can cause multiple cardiac complications, and stent thrombosis is one of them, although it is rarely mentioned in the literature. Thus, a history of previous cardiac events may facilitate these incidents. However, cardiac complications may occur in the absence of a cardiac disease history. There are different mechanisms through which $\mathrm{CO}$ poisoning may be linked to myocardial ischemia, and we can speculate that thrombus aggregation in the myocardial arteries is the most important one. This report describes a very rare case of CO poisoning with very late thrombosis of a tacrolimus drug-eluting stent. In particular, patients who have undergone coronary stenting, particularly those in whom drug-eluting stents have been implanted, should be carefully investigated for AMI, stent thrombosis, or any other cardiac complications in the emergency room after $\mathrm{CO}$ poisoning.

Informed Consent: Written informed consent was obtained from patient who participated in this study.

Peer-review: Externally peer-reviewed.

Author contributions: Concept - S.Ö., I.D., S.A.; Design - S.Ö., I.D., S.A.; Supervision - S.Ö., I.D., S.A.; Resource - S.Ö., I.D., F.E.; Materials - S.Ö., S.A., A.E.; Data Collection and/or Processing - S.Ö., F.E., I.D.; Analysis and/or Interpretation - S.Ö., A.E., I.D.; Literature Search - S.Ö., I.D., S.A.; Writing - S.Ö., I.D., S.A.; Critical Reviews - S.A., A.E., F.E.
Conflict of Interest: No conflict of interest was declared by the authors.

Financial Disclosure: The authors declared that this study has received no financial support.

\section{References}

1. Lippi G, Rastelli G, Meschi T, Borghi L, Cervellin G. Pathophysiology, clinics, diagnosis and treatment of heart involvement in carbon monoxide poisoning. Clin Biochem 2012; 45: 1278-85.[CrossRef]

2. Dileo PA, Tucciarone M, Castro ER, Guerrero M. Late stent thrombosis secondary to carbon monoxide poisoning. Cardiovasc Revasc Med 2011; 12: 56-8. [CrossRef]

3. Hsu PC, Lin TH, Su HM, Lee HC, Huang CH, Lai WT, et al. Acute carbon monoxide poisoning resulting in ST elevation myocardial infarction: a rare case report. Kaohsiung J Med Sci 2010; 26: 271-5. [CrossRef]

4. Weaver LK. Clinical practice. Carbon monoxide poisoning. N Engl J Med 2009; 360: 1217-25. [CrossRef]

5. Alonso JR, Cardellach F, Lopez S, Casademont J, Miro O. Carbon monoxide specifically inhibits cytochrome c oxidase of human mitochondrial respiratory chain. Pharmacol Toxicol 2003; 93: 142-6. [CrossRef]

6. Iheagwara KN, Thom SR, Deutschman CS, Levy RJ. Myocardial cytochrome oxidase activity is decreased following carbon monoxide exposure. Biochim Biophys Acta 2007; 1772: 1112-16. [CrossRef]

7. Raub JA, Mathieu-Nolf M, Hampson NB, Thom SR. Carbon monoxide poisoning: a public health perspective. Toxicology 2000; 145: 1-14. [CrossRef]

8. Nielsen VG, Arkebauer MR, Vosseller K. Redox-based thrombelastographic method to detect carboxyhemefibrinogen-mediated hypercoagulability. Blood Coagul Fibrinolysis 2011; 22: 657-61. [CrossRef]

9. Grace TW, Platt FW. Subacute carbon monoxide poisoning. Another great imitator. JAMA 1981; 246: 1698-1700. [CrossRef] 